\title{
Bilateral clear cell acanthoma of the areola and nipple: good response to topical corticosteroids*
}

\author{
Elena González- Guerra ${ }^{1}$ \\ Jorge Ruiz Rodriguez ${ }^{2}$ \\ Alejandro Fueyo Casado ${ }^{1}$
}

\author{
Alberto Conde Taboada ${ }^{1}$ \\ Jose Antonio Cortes Toro ${ }^{3}$ \\ Eduardo Lopez Bran ${ }^{1}$
}

DOI: http:/ /dx.doi.org/10.1590/abd1806-4841.20175683

\begin{abstract}
Clear cell acanthoma is a rare, epidermal tumor not common in the area of the nipples; indeed, the literature describes only 8 cases, all showing unilateral presentation. We here report the first case of bilateral clear cell acanthoma with good response to topical corticosteroids. Case report: A sixteen-year old girl presented with 2 excrescent, fleshy, and exudative tumor masses in both nipples and areola mammae. A biopsy was conducted and confirmed clear cell acanthoma histopathologically. Treatment with strong corticosteroids resulted in rapid improvement and resolution. After one year of follow-up, the patient developed atopic dermatitis. Discussion: We describe the first case of bilateral clear cell acanthoma localized in the nipple/areola that resolved with powerful corticosteroids, suggesting a reactive etiology of the lesion.
\end{abstract}

Keywords: Acanthoma; Adolescent; Clobetasol; Nipples

\section{INTRODUCTION}

Clear cell acanthoma (CCA), also known as pale cell acanthoma, Degos acanthoma and Degos and Civatte clear cell acanthoma, is a rare, benign, epidermal tumor that occurs as single or multiple lesions. ${ }^{1}$ In the past, some authors deemed it to be a variety of seborrheic keratosis or senile lentigo (especially when pigmented), though today it is universally regarded as an independent, benign, epithelial neoplasm. ${ }^{2}$

Typically it occurs as a single lesion on the lower part of the legs (either face), and sometimes in the thighs. However, lesions located in other areas have been described as well as lesions with differences in size, shape and number, and also an eruptive form involving hundreds of lesion. Eight cases have been reported involving the nipple area and showing unilateral presentation. ${ }^{2-5} \mathrm{Sev}-$ eral treatments were tried with variable results. The present work describes the first bilateral case of CCA located in the nipple/areola mammae with good response to topical corticosteroids.

\section{CASE REPORT}

A sixteen-year old girl from the Philippines with no relevant personal or family history came to consultation for the presence of lesions on both nipples/areola mammae. These had been present since the beginning of puberty at the age of 12 years. Lesions produced constant pruritus, stinging and exudation.

Upon physical examination, two well-defined, excrescent, fleshy, violaceous and exudative tumoral masses were revealed affecting both nipples/areola mammae (Figure 1). Dermoscopy showed globular vessels arranged in a linear, string of pearls distribution. Biopsy was performed on the one of the lesions. Findings included a markedly acanthotic epidermis with fused rete ridges (Figure 2). Individual cells showed clear cytoplasm due to the presence of abundant glycogen (demonstrated by the periodic acid Schiff reaction). Basal membrane conserved its normal color characteristics under hematoxylin-eosin. Both dermis and epidermis showed infiltration by neutrophils and eosinophils (Figure 3).

Work submitted on 09.02.2016

Approved by the Advisory Board and accepted for publication on 09.08.2016

* Study conducted at the Servicio de Dermatología. Hospital Clinico San Carlos - Madrid, Spain.

Financial Support: None.

Conflict of Interests: None.

Department of Dermatology, Hospital Clínico San Carlos - Madrid, Spain.

Department of Gynecologist and Obstetrics. Hospital Clínico San Carlos - Madrid, Spain.

Department of Pathological Anatomy, Hospital Clínico San Carlos - Madrid, Spain.

(C2017 by Anais Brasileiros de Dermatologia 


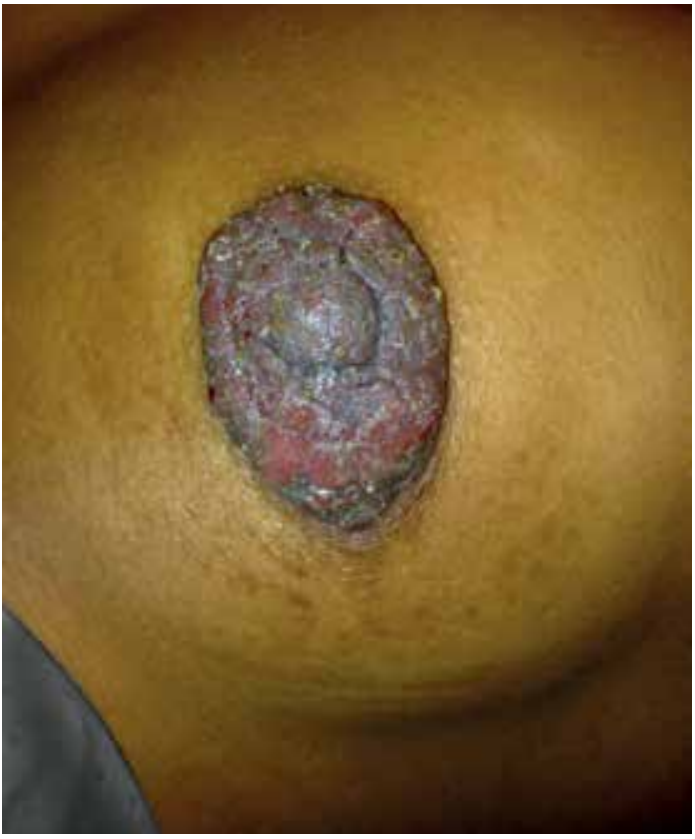

Figure 1: A bright-red, exudative, lobulated plaque with a crusty surface on the right nipple and areola

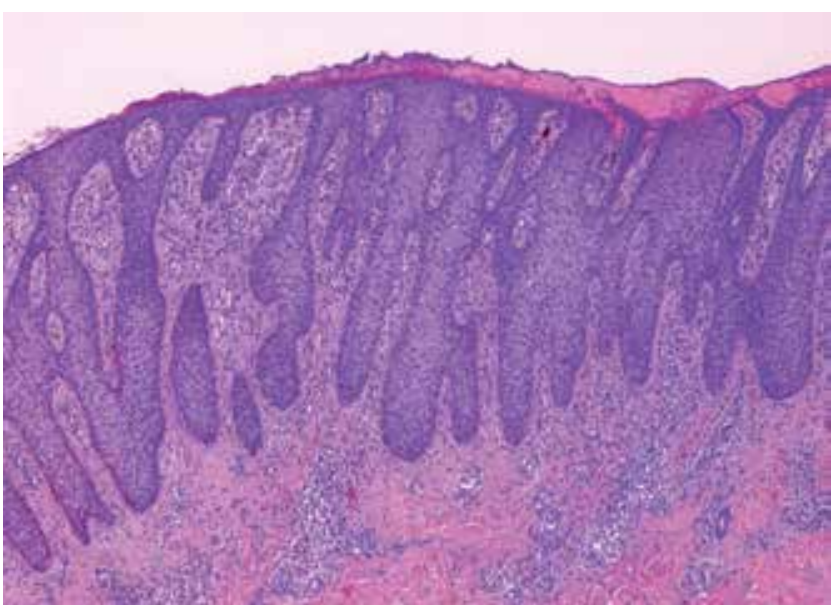

FIGURE 2: Markedly acanthotic epidermis, with fused rete ridges. Clear cell in the Malpighian layer (Hematoxylin \& eosin, X10)

Treatment begun with clobetasol propionate cream $0.05 \%$, applied twice daily with occlusive dressing. Rapid improvement was seen and lesions disappeared after 3 months of treatment (Figure 4). During 1 year of follow-up, patient showed hyperkeratosis pilaris on the outer face of both arms and on her face, plus flexural eczema. A diagnosis of atopic dermatitis was reached for this condition.

\section{DISCUSSION}

CCAs etiology remains unknown. These tumors are, however, generally considered benign, epidermal neoplasms given their

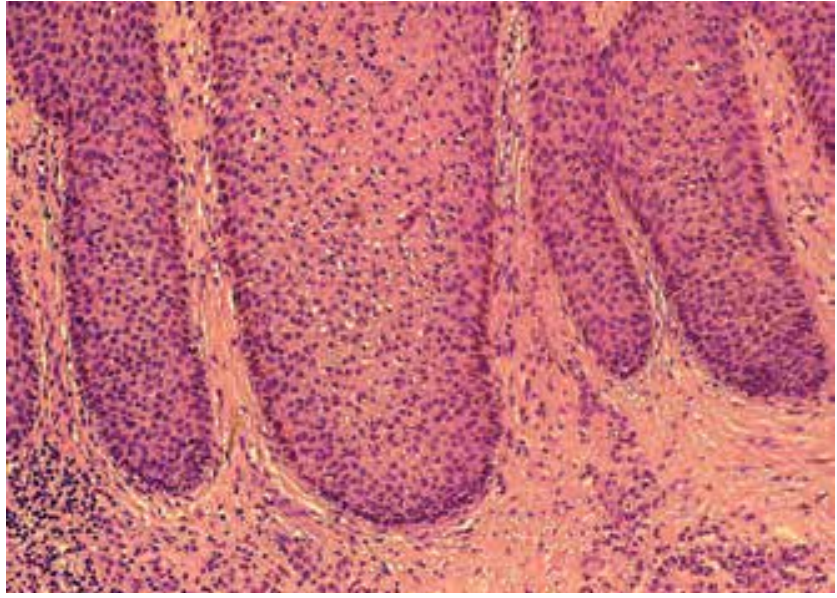

FIgURE 3: Individual cells showing clear cytoplasm. The epidermis and dermis showed infiltration by neutrophils and eosinophils (Hematoxylin \& eosin, X40)

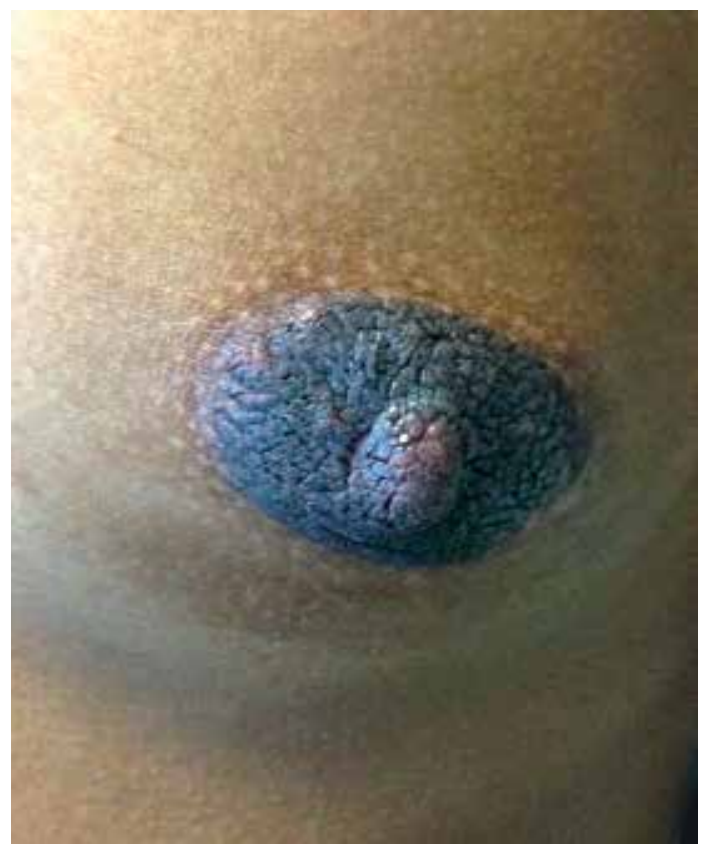

Figure 4: Treatment led to rapid improvement, with disappearance of lesions after 3 months

expression of involucrins, and epithelial membrane antigens. This suggests that CCAs derive from the surface epithelium or the external epithelial shell of hair follicle. ${ }^{1}$ Nonetheless, some authors report CCA concurrent with syringofibroadenomatous changes (in 9 of 47 patients examined), suggesting it may derive from the eccrine apparatus. ${ }^{6}$ The most recent literature suggests that CCA may be a reactive phenomenon rather than a true neoplasm given its expression of cytokeratins similar to those seen in other forms of inflammatory dermatosis. ${ }^{2,4,7}$ 
In many cases, dermoscopy allows a confident diagnosis to be made via observation of a very characteristic pattern involving widespread pinpoint-like, dotted and/or glomerular vessels, linearly arranged like a string of pearls, producing a network-like structure. ${ }^{5}$ However, given its clinical variability, CCA is often only recognized after histological examination.

CCA in the nipple area is uncommon; only 8 cases have ever been described. ${ }^{2,3,48,9}$ In all cases it affected young patients aged 1425 years; only 1 patient was male. In the present study, patient was a 16 year-old girl. All of the reported cases were unilateral CCA. Our patient presented bilateral CCA that started simultaneously with puberty. In the 8 reported cases a reactive etiology was proposed: most patients also simultaneously suffered from atopic dermatitis. The present patient also developed this complaint.

Many treatments for CCA have been proposed reaching variable results. Certainly, the condition does not spontaneously regress if appropriate treatment is not applied. Surgical excision or physical ablation with liquid nitrogen or $\mathrm{CO}_{2}$ laser is effective. Nevertheless, this type of treatment given frequently results in comor- bidity or psychological aversion or may leave scars and unaesthetic results. For these reasons we did not try those treatments as first option in our case. For large and multiple lesions, for lesions located on bone prominences, and in patients undergoing anticoagulation treatment who are not eligible for surgery, complete resolution of the condition and good aesthetic results have been achieved with liquid nitrogen cryotherapy. Some authors report the use of calcipotriol to treat CCA, with good and stable response. ${ }^{5}$ In the present patient, treatment with strong topical corticosteroids reached good results with no relapse after 1 year follow-up. To date, cases of CCA affecting nipples/areola have all involved young patients, most of whom also suffered from atopic dermatitis. ${ }^{3}$ Eventual development of this condition by the present patient once again suggested that CCA have a reactive etiology.

In conclusion, this paper describes the first bilateral case of CCA affecting the nipple/areola mammae of a young patient who developed atopic dermatitis. Lesions, which may have been reactive in etiology, responded very well to strong corticosteroids.

\section{REFERENCES}

1. Herrera E, Gallardo M, López N. Acantoma de células claras. In: Herrera E, Moreno A, Requena L, Rodriguez JL. Dermatopatologia: correlación clínico patológica. Barcelona: Signament Edicions, 2007.p. 19-22

2. Park SY, Jung JY, Na JI, Byun HJ, Cho KH. A case of polipoid clear cell acanthoma on nipple. Ann Dermatol. 2010;22:337-40.

3. Nazzaro G. Clear cell acanthoma of the nipple: another report from Italy. An Bras Dermatol. 2014;89:189.

4. Veiga RR, Barros RS, Santos JE, Abreu Junior JM, Bittencourt Mde J, Miranda MF. Clear cell acanthoma of the areola and nipple: clinical, histopathological, and immunohistochemical features of two Brazilian cases. An Bras Dermatol. 2013 ;88:84-9.

5. Scanni G, Pellacani G. Topical calcipotriol as a new therapeutic option for the treatment of clear cell acanthoma. An Bras Dermatol. 2014 Sep-0ct;89(5):803-5.

6. Shalin SC, Rinaldi C, Horn TD. Clear Cell acanthoma with changes of eccrine syringofibroadenoma: reactive change or clue to etiology? J Cutan Pathol. 2013;40:1021-6.
7. García-Gavín J, González-Vilas D, Montero I, Rodríguez-Pazos L, Pereiro MM, Toribio J. Disseminated eruptive clear cell acanthoma with spontaneous regression: further evidence of an inflammatory origin? Am J Dermatopathol. 2011;33:599-602.

8. Kim DH, Kim CW, Kang SJ, Kim TY. A case of clear cell acanthoma presenting as nipple eczema. Br J Dermatol. 1999;141:950-1.

9. Nazzaro G, Coggi A, Gianotti R. A 26 year old man with an eczematous lesion on the nipple. Arch Dermatol. 2012;148:641-6.
MAILING ADDRESS:

Elena González-Guerra

Profesor Martín Lagos s/n

28040 Madrid, Spain.

Email:elenagonzalezguerra@yahoo.es

How to cite this article: González- Guerra E, Conde Taboada A, Ruiz Rodríguez R, Cortes Toro JA, Fueyo Casado A, Lopez Bran E. Bilateral clear cell acanthoma of the areola and nipple: good response to topical corticosteroids. An Bras Dermatol. 2017;92(5 Suppl 1): $27-9$. 